\title{
Língua e romance na globalização
}

\begin{abstract}
This essay approaches linguistic and cultural issues associated with globalization, language and the novel in order to demonstrate how the novel as a literary genre can express the tensions of globalization. The main theoretical basis is Mikhail Bakhtin's theory of language and the novel. Concerning language the paper recalls the discrepancy between the linguistic thought of Bakhtin's circle and the structural linguistics by Ferdinand de Saussure, emphasizing that a linguistic based on utterance enables a suitable link between structural system and society. The paper explains the difference between centripetal and centrifugal forces of language, according to Bakhtin and their relationship with globalization. It also explains Bakhtin's concept of the novel, stressing the relationship of the genre as a dialogic plurality of discourses, in order to demonstrate how suitable the novel is to express the globalized world. Theories of globalization are confronted and the problems related to globalization are exposed. Following Milton Santo's thought, the paper reflects on the possibility of another globalization, not only expansive, but also integrative. By commenting the cultural situation of certain writers and their attempts to express it, this essay combines Bakhtin's thought with theories of globalization in order to point out possible responses of contemporary novel.
\end{abstract}

Keywords: Mikhail Bakhtin; linguistics; discourse; literaty genres; novel; globalization.

Resumo: Este ensaio aborda questões linguísticas e culturais associadas à globalização, à língua e ao gênero romance, a fim de demonstrar que esse gênero literário pode expressar as tensões da globalização. A principal base teórica é o pensamento de Mikhail Bakhtin. No que diz respeito a linguagem este trabalho inicia-se chamando a atenção para a discrepância entre o pensamento linguístico do círculo de Bakhtin e a Linguística Estrutural de Ferdinand de Saussure, enfatizando que os estudos linguísticos baseados no enunciado permitem uma ligação adequada entre o sistema linguístico e a vida social. O ensaio explica a distinção, por Bakhtin, entre forças centrípetas e centrífugas da linguagem e sua relação com a globalização. Ele também explica o conceito do romance de Bakhtin, destacando a relação do gênero como pluralidade dialógica dos discursos, a fim de demonstrar a adequação do romance para representar o mundo globalizado. Teorias da globalização são confrontadas e os problemas relacionados com a globalização são expostos. Seguindo o pensamento de Milton Santos, este ensaio reflete sobre a possibilidade de uma outra globalização, não só expansiva, mas também integrativa. Ao comentar a situação cultural de certos escrito-

1 Professor Adjunto de Teoria da Literatura na Universidade de Brasília. Doutor em Estudos Comparados de Literatura. Coordenador do Grupo de Pesquisa 'Literatura e Cultura.' Atualmente centra seus estudos e Cursos em torno da Filosofia do Círculo de Bakhtin e na produção literária do escritor Osman Lins. 
res e as suas tentativas de expressá-la, este ensaio combina pensamento de Bakhtin com as teorias da globalização, a fim de apontar possíveis respostas do romance contemporâneo.

Palavras-chave: Mikhail Bakhtin; Linguística; discurso; romance; globalização.

Tratar de língua e literatura no contexto globalizado demanda uma abordagem transdisciplinar, porque esse contexto envolve questões políticas, antropológicas, econômicas e sociológicas, entre outras. Não pretendo esgotar o tema, muito menos contemplar igualmente todas as disciplinas que o objeto demanda. Em vez disso, baseio-me em algumas reflexões de Mikhail Bakhtin, cujo pensamento é muito propício para uma análise da situação das línguas e da literatura na era globalizada. A obra do Círculo de Bakhtin temse mostrado cada vez mais relevante não somente para a Linguística e para os estudos da Literatura, mas também para as demais ciências humanas, já que resulta de uma atividade intelectual que não se limita a um campo científico, mas se localiza, no dizer de Bakhtin, nas fronteiras entre diversas ciências.

Iniciando sua obra em um momento histórico cuja prioridade era demarcar rigorosamente as fronteiras do discurso literário ou se estudar a Literatura como resultado direto de fatores econômicos, Bakhtin enfatizou a necessidade de se estudarem as relações da Literatura com outros discursos e com outros elementos da cultura. Portanto, sugere uma abordagem da Literatura que se pode chamar de "antropológica". Já no que diz respeito ao estudo da língua, Bakhtin ultrapassa os limites da estrutura e explora o domínio do enunciado. Com isso, explora o caráter social da língua, já apontado, mas não devidamente explorado por Saussure. Sua concepção de língua é fundamental para se estudar as relações entre língua e ideologia, pois os enunciados enformados em gêneros do discurso é que articulam o sistema linguístico com o ambiente social.

Com base nas reflexões do Círculo de Bakhtin, passo a abordar a tensão entre forças de unificação (centrípetas) e forças de estratificação e dispersão linguística (centrífugas) e o dialogismo que envolve essa tensão, o modo de operação estilística do romance tanto no contexto linguístico quanto no contexto da cultura de modo geral; a maneira como esses fenômenos se manifestam na atualidade e são percebidos pelos romancistas no mundo globalizado; e as possíveis respostas estilístico-ideológicas do romance.

Ferdinand de Saussure (2001) observa que a língua não é um fenômeno estático, mas dinâmico, como tudo na cultura. Uma das oposições do pensamento de Saussure é justamente aquela entre diacronia e sincronia. A visão diacrônica permite que se percebam as transformações linguísticas ao longo do tempo e a visão sincrônica é um corte artificial, em que, para conveniência de análise, se toma provisoriamente como estático um sistema que está em constante transformação. Mas a língua também se transforma no espaço. A dispersão dos homens no espaço, em épocas cujos meios de transporte e de comunicação eram muito primitivos, criou a diversificação linguística ao longo do tempo. Por outro lado, os contatos e empreendimentos comuns desenvolvidos por povos diferentes têm contribuído para certos fenômenos de convergência linguística, como os crioulos, os pidgins e as línguas francas. Contrariando o mito bíblico, a expressão Torre de Babel, usada para expressar confusão linguística, deveria ter um sentido contrário: o sentido de uma pressão unificadora ou hibridizante. É isto que acontece com essa grande Torre de Babel invertida - isto é, homogeneizante -, que é a globalização. Mas, como a torre bíblica, a torre globalizada também tem seus pecados, como, por exemplo, o sufocamento de línguas e de tradições. No entanto, ela 
não logra destruir a diversidade, que resiste e se refaz em meio à língua e ao pensamento comum. Esta transparece nas convergências e resistências que geram processos de hibridização da língua e da cultura hegemônica com as línguas e as culturas locais, em processos que ora são mais harmônicos, ora mais tensos, conflituosos, chegando a ser violentos.

Também no interior daquilo que normalmente se apresenta como a língua de uma nação existe tensão entre unificação e diversidade. Bakhtin distingue forças de centralização linguística (forças centrípetas) e forças de estratificação (forças centrífugas). A unificação linguística pode ocorrer espontaneamente, em comunidades muito pequenas ou em situações que demandam um entendimento comum, mesmo provisório, entre várias comunidades linguísticas reunidas, como é o caso das feiras, dos acordos, ou mesmo das guerras. No entanto, uma unificação mais extensiva e duradoura, normalmente acontece por pressões políticas e econômicas e por ações institucionais. Assim é a língua padrão de um país, com sua gramática normativa. Por outro lado, as forças de estratificação são muito mais espontâneas, pois, na verdade, a língua única é uma construção oficial que sobressai na diversidade de formas populares.

Ao elaborar sua teoria do romance, Bakhtin defende uma abordagem estilística desse gênero como o que melhor explora a diversidade linguística, em oposição aos gêneros poéticos clássicos, voltados para a unificação. A limitação dos estudos estilísticos do romance, segundo Bakhtin, deve-se à influência de uma noção de linguagem poética pura, herdada da poética clássica e dos estudos filológicos (BAKHTIN, 2015, p. 23-27). Todo ser humano vive em um mundo povoado pelas mais diversas variedades linguísticas e discursivas, mas a heterogeneidade linguística e, principalmente, discursiva é a matéria prima por excelência do romance, ao contrário do que acontece com os gêneros poéticos clássicos. Por isto, Bakhtin (2015, p. 27) caracteriza o romance como heterodiscursivo, pluriestilístico e heterovocal. Não se deve entender esta afirmação no sentido de que o romance seja uma colcha de retalhos linguística, uma mera justaposição de linguajares. Em que pese algumas traduções utilizarem o termo "plurilíngue" em vez de "pluridiscursivo", não se trata de variantes puramente formais da língua ou da simples incorporação de dialetos conjugados com a língua oficial, mas do confronto dialogizado de discursos diversos. Assim, o romancista, em vez de trabalhar com a verdade absoluta de uma língua suprema, trabalha com as tensões ideológicas entre discursos que se criticam mutuamente. Uma das maiores qualidades do romancista é essa sensibilidade para a linguagem e a visão de mundo do outro, e para as tensões entre as visões de mundo expressas por cada variedade linguística e discursiva. No romance, os discursos não são apenas justapostos como simples variedades linguísticas, mas interagem e polemizam como representantes de visão de mundo de grupos específicos. Assim, o romance representa a luta discursiva - que também é ideológica - que caracteriza a existência social da língua, principalmente nas sociedades mais complexas.

Bakhtin afirma que, no seu auge, o romance tem uma influência avassaladora no sistema literário, chegando a "romancizar" os demais gêneros, isto é, emprestar-lhes algumas características do heterodiscurso dialogizado. Mas de onde vem essa força do romance? Certamente não do gênero como pura forma, mas da sociedade que o elege e o favorece. Para Bakhtin, todo gênero - literário ou não - origina-se de uma necessidade pragmática. $^{2}$ No entanto, o gênero, assim com a língua, não é invenção exclusiva do autor (no

2 Para certa concepção romântica de poesia lírica - hoje consolidada popularmente (embora questionada) - resposta puramente subjetiva do gênio individual, soa estranha a associação das formas da antiga lírica grega com funções sociais específicas. Por exemplo, o encômio com função de homenagem, a elegia como canto fúnebre, o epitalâmio como canto nupcial, o epinício ou ode triunfal como canto de vitória esportiva. 
caso da literatura), nem do falante (no caso dos demais gêneros do discurso): é criado e se desenvolve para atender a determinadas demandas sociais. Assim, ele não é criado apenas para atender a demanda do escritor ou falante, mas também da comunidade linguística em que é produzido. Portanto, se o romance mudou de status, passou de gênero ignorado pela poética clássica para centro do cânone literário do Ocidente, cabe perguntar o que mudou na sociedade, porque a sociedade se passou a valorizar cada vez mais os traços romanescos.

Bakhtin apresenta algumas explicações sobre os contextos históricos que favorecem o desenvolvimento não somente do romance enquanto forma, mas de uma visão romanesca do mundo. Os períodos mais favoráveis ao romance são períodos de crise, com a desestabilização de hábitos e crenças arraigadas. É o caso do período helenístico da cultura grega, com a decadência da polis; do Renascimento, quando transformações econômicas, novas maneiras e pensar, novas tecnologias e descobertas e contato mais intenso com culturas exóticas - incluindo a descoberta do continente americano - desestabilizam os dogmas do mundo medieval. Enfim é o caso do mundo moderno, no qual podemos incluir esta fase contemporânea que se costuma denominar pós-modernidade.

Observando, no romance, algo mais que uma epopeia burguesa, Bakhtin aponta o diálogo socrático e a sátira menipeia como gêneros precursores do romance, no que diz respeito a suas qualidades estilísticas. Mas, ao associar o romance a esses gêneros, Bakhtin tem em mente não apenas o uso da prosa coloquial e da mistura de estilos, mas também visões de mundo específicas, menos míticas e mais racionais, críticas, irônicas. É também por causa dessa visão específica que o diálogo socrático é invocado, embora seja produto do período ático da civilização grega. No diálogo socrático - provavelmente mais na oralidade original que na estilização platônica - encontramos um discurso desestabilizador de verdades antigas. Já a sátira menipeia é muito praticada, no período helenístico, embora criada anteriormente. O fato de seu principal representante ser Luciano, autor de origem síria (provavelmente de formação bilíngue e cultura híbrida), exprime bem a nova situação política e cultural dos gregos com a dissolução da polis. O mesmo acontece com o chamado romance grego, ou sofístico, considerado, pelo helenista Jacinto Lins Brandão, um gênero pós-antigo (BRANDÃO, 2005, P. 34). Assim, não é por acaso que a sátira menipeia é redescoberta e renovada no Renascimento, como parte da revolução cultural que inicia o período moderno.

Outra característica fundamental do romance é o seu inacabamento, tanto no sentido formal, quanto na visão de mundo que expressa. Ao contrário dos gêneros clássicos, com suas formas claramente definidas, o romance é um gênero inacabado, sempre apto a novas transformações. Além disso, o romance representa um mundo inacabado, não concluído, cuja dinâmica não é bem apreendida pelos outros gêneros. Com sua capacidade de adaptação, o romance se renova na expressão do contexto globalizado, pós-colonial, pósmoderno. Nesse processo de renovação, o romance apreende as condições linguísticas e socioculturais da globalização.

Entre vários outros aspectos que estruturam esse fenômeno complexo, está a hegemonia de certos idiomas, nacionais ou coloniais, em detrimento Dos dialetos locais. Trata-se, na verdade, da aceleração e da expansão de um processo que começou com a formação dos estados nacionais, passando pelas ocupações coloniais e que agora acontece em nível

Contudo, essa relação entre lírica e sociedade confirma a visão de Bakhtin sobre os gêneros. A subjetividade da lírica é também é resultado de uma demanda social, pois, a certa altura, no mundo ocidental, a demanda pragmática do texto literário e, mais ainda, do texto lírico, foi se apresentar como puramente estético e nada pragmático, distinguindo-se dos discursos utilitários da sociedade. 
planetário. Em todos os casos, a tensão é a mesma: temos por um lado, a pressão por uma língua unificada, por valores homogêneos e por uma cultura e uma técnica hegemônica em tensão com as tradições locais. Nesse processo, certamente línguas e tradições são sacrificadas. Mas outras línguas e tradições conseguem resistir, embora não permaneçam intactas. Uma das formas de resistência é justamente a hibridização, entendida não como simples mistura ou mestiçagem, mas como um processo contínuo, em que a língua e as técnicas hegemônicas são combinadas com as línguas e tradições locais, como demonstra Nestor Garcia Canclini (CANCLINI, 2008), ao estudar esse processo nos países latino-americanos. Enfim, embora o contato da cultura hegemônica com as culturas locais baseiese em uma assimetria de poder com forte pressão homogeneizadora, nenhuma delas permanece intacta neste encontro de línguas e culturas. Isto acontece, em grande parte, como efeito colateral da própria globalização, pelo fato de ela não ser um processo igualitário.

Para Milton Santos, a expressão "aldeia global" pode ser ilusória, pois os padrões globalizados ultrapassam com muito mais facilidades fronteiras nacionais que fronteiras sociais ou fronteiras regionais, se pensarmos, por exemplo, na diferença entre o ambiente rural e o ambiente urbano, que ainda é muito acentuada em grande parte do mundo. Mas, mesmo nas classes mais altas e nas populações urbanas, essa assimilação do padrão global é seletiva, sempre resultando de uma negociação com os costumes locais. Além do fato de que a hibridação já aconteceria normalmente pelo contato de culturas, apesar da pressão homogeinizadora, o próprio caráter excludente da globalização contribui para processos híbridos mais intensos, que são processos de resistência. Não devemos esquecer que a globalização, ao mesmo tempo em que cria condições similares para o fluxo de capital e mercadorias, não elimina, por si só, as desigualdades do capitalismo. Como observa Milton Santos, a percepção crítica dessa situação é o primeiro passo para se buscar e lutar por outra globalização, não somente expansionista, mas integradora.

Cabe agora analisar como fica arte do romancista nesta situação: que adaptações o romance precisa sofrer para expressar criticamente este tipo de mundo. Esta questão diz respeito à matéria-prima do romancista, que é a língua, entendida não como pura forma, mas como fonte e portadora de uma série de valores culturais: como discurso. No mundo pós-colonial, isto é, no mundo dessa nova forma de colonialismo, que é a globalização, as línguas coloniais - incluindo a língua franca global atual, que é o inglês - impõem-se, por razões práticas e ideológicas, sobre as línguas locais. Mas os dialetos locais também deixam suas marcas nas línguas hegemônicas. É o que acontece com o português do Brasil, com suas marcas tupi e africana e com várias outras línguas coloniais espalhadas em diversos continentes.

Tensões de política linguística são ainda mais agudas em países onde a língua do colonizador não logrou destruir as línguas locais; onde essas línguas são intensamente utilizadas. É o caso de Angola, de Moçambique, da Índia e da Indonésia, só para citar alguns exemplos. O mesmo processo envolve outros elementos da cultura: o racionalismo burguês ocidental defronta-se com outras formas de pensar; a ciência confronta-se com outras visões do mundo; a tecnologia industrial abala, mas nem sempre destrói, o artesanato local. É o que se expressa na obra do moçambicano Mia Couto, que, em um português cheio de termos africanos, mostra também o contraste entre os valores e a visão de mundo herdados do colonizador com os costumes e as formas de pensamento locais. Essa diversidade pode estar plena de contrastes e confrontos agudos, às vezes violentos, como se vê, por exemplo, na obra de Salman Rushdie, que explora conflitos - não somente políticos, mas também psicológicos - entre diferentes mundos culturais, em persona- 


\section{Conexão Letras}

gens que precisam negociar, conciliando, negando ou superando, diferenças de valores, criando uma identidade híbrida, tornando-se uma "pessoa traduzida" (CARREIRA, 2004, p. 1). Em relação às tensões da variedade linguística na Índia, o narrador de Filhos da meia-noite, de Rushdie, afirma: "manifestantes pelas línguas exigiram a divisão do estado de Bombaim de acordo com as fronteiras linguísticas (...). Em 1956, então, as línguas marcharam em manifestação pelas ruas durante o dia; à noite, se revoltaram na minha cabeça”. (RUSHDIE, 1995, p. 167).

Por outro lado, o uso de uma língua franca, embora permita a comunicação, não garante para uma compreensão mútua profunda. Isto é ilustrado no romance Avalovara , do escritor brasileiro Osman Lins (1924-1978), quando o protagonista masculino, o aspirante a escritor Abel, comenta a impossibilidade de expressar seu mundo geográfico e cultural para sua namorada alemã Anneliese Roos :

A língua de Racine, que utiliza de um modo literário, digno e até elaborado na qual a exatidão seria a única falha, adquire, interposta entre idiomas diferentes - o idioma que cada um de nós traz do país de origem e que o outro não fala -, um sentido mágico e benévolo; nós, sem ela, dois mudos. As vias que nos abre, contudo, são limitadoras e mais para mim do que parra Roos: raras vezes, e talvez nunca, expresso com exatidão o que me esforço para dizer-lhe.

Assim, não obstante o meu fervor, nossas conversações, flutuando numa órbita até certo ponto neutra, alheia igualmente à atmosfera da pequena cidade alemã onde nasce Anneliese Roos e à parte do Nordeste que - sempre sem êxito - tento descrever-lhe, ilustram, para meu desespero as limitações da linguagem e mais ainda as do escritor, egresso, com freqüência, de territórios pouco familiares. (LINS, 2005, p. 96)

A relação amorosa frustrada entre Abel e Anneliese Roos, como o próprio autor afirma em uma entrevista (LINS, 1979, p. 218) refere-se a uma mistura de fascínio do escritor brasileiro (mas eu poderia dizer: cada escritor de um país colonizado) com a cultura europeia - e, ao mesmo tempo, a clara percepção de seu pertencimento a um mundo cultural diferente, apesar de a herança Europeia legada pela colonização. A relação entre os dois personagens acontece em um clima de erotismo tenso, que nunca leva à satisfação sexual. Essa incompatibilidade é representada alegoricamente pela descrição das escadas do Castelo de Chambord:

Tento perguntar - e desisto, enervado, invocando um auxílio verbal que não possuo - se atentou em Chambord para a dupla escadaria no centro do castelo. Duas pessoas que usam ao mesmo tempo, Roos, essas duas escadas helicóides, vêem-se mas não se encontram. Talvez ali esteja escrito, ou esboçado - eis o que desejo dizer-lhe e não consigo -, o destino de muitos. O nosso, inclusive. Não iremos subir a mesma escada, Roos, por mais que eu-e talvez você - desejo o contrário. Tanto uma escada como outra levavam a belos aposentos, com leitos baldaquinados. Mas uma mulher e um home só podiam ocupar a mesma cama se subissem a mesma escada. Como dizer isto e acrescentar que eu desejaria esgueirar-me entre os balaústres, unir-me a ela em todos os sentidos? (LINS, 2005, p. 96-97)

É importante ter em mente que a globalização expande um tipo de tensão linguística que já existia (e ainda existe) em nível nacional. Durante a Idade Média, as línguas locais (referidas como "vulgares") coexistiram com o latim, mas cada língua tinha o seu lugar fixo: latim para a religião, erudição e diplomacia; e línguas vulgares para a vida diária. $\mathrm{O}$ latim era a língua da literatura - entendida como textos eruditos - e as línguas vulgares 
eram empregadas em grande parte da poesia oral. Diálogos paródicos entre os dois âmbitos linguísticos aparecem, por exemplo, em Carmina Burana, uma coleção de poemas - a maioria bilíngue - escritos por um clero de monges errantes conhecidos como goliardos. No entanto, a tensão não era tão forte quanto hoje, porque o latim já era uma língua morta: não houve supremacia de uma determinada nação (como aconteceu com o latim durante $o$ Império Romano), mas a supremacia das instituições: a Igreja e, depois, as universidades. A tensão aumenta com a emergência das línguas nacionais, que se destacam em luta, quer com o latim, bem com os dialetos regionais. De acordo com Bakhtin a tradução de livros para várias línguas nacionais contribuiu para aprimorar as características do romance: "Pode-se dizer francamente que a prosa romanesca europeia nasce e elabora-se no processo de tradução livre (reenformadora) de obras alheias" (BAKHTIN, 2015, p. 181). Se a tradução para as línguas nacionais forneceu material para desenvolver o romance, por outro lado a literatura produzida em línguas nacionais e locais contribuiu para consolidar identidades nacionais e, mesmo, em menor escala, regionais, contribuindo para criar o que Benedict Anderson denomina "comunidades imaginadas". (ANDERSON, )

A tensão entre as forças centrípetas e centrífugas ocorre em qualquer Estado-nação, especialmente naqueles de forte diversidade linguística; e tem sido muito aguda nos países colonizados, com a imposição de língua do colonizador. Mas, pelo menos em terras de colonização católica, a catequese dos indígenas demandou, no início, que os padres aprendessem e empregassem línguas nativas. No Brasil, os jesuítas escolheram e desenvolveram uma língua franca já empregada pelos nativos, o tupi-guarani, para a sua tarefa de conversão. Este é o início de uma linguagem híbrida (e neste caso, uma criação poética híbrida), empregada na obra dramática do Padre José de Anchieta, como explica Alfredo Bosi: "O poeta procura, no interior dos códigos tupis, moldar uma poética bastante próximas das medidas trovadorescas, em suas variantes populares ibéricas: com o verso redondilho forja quadras e quintilhas na qual se arma um jogo de rimas ora alternadas ora opostas" (BOSI, 1992, p. 64). Falante nativo de espanhol que domina o português, Anchieta sentiu a necessidade de compor obras dramáticas em tupi, ou permeadas por termos tupis, e enfrentou a grande dificuldade de adaptar o vocabulário tupi para expressar noções cristãs, criando assim uma espécie de teologia que só lograva traduzir muito imperfeitamente o pensamento original que pretendia transmitir.

Essa hibridação foi inibida mais tarde, em uma espécie de poética neoclássica resultou da divisão entre a língua de uma elite letrada e a língua do povo, a qual continuou a ser muito influenciada, no vocabulário e pronúncia, pelo tupi e por línguas africanas. Essa divisão é criticada por Mário de Andrade (1893-1945). Sua narrativa Macunaíma chamada de rapsódia pelo próprio autor - é provavelmente a obra mais rabelaisiana da Literatura Brasileira. Escrita em uma espécie de Português Brasileiro coloquial permeado por vocabulário de origem indígena e africana, que apresenta todas as características analisadas por Bakhtin (1984) nas obras de Rabelais: intenso emprego da paródia, imagética grotesca e humor carnavalesco. Pode-se dizer que Mário de Andrade pôs a cultura erudita em relação dialógica com a cultura popular no português do Brasil, o mesmo que Rabelais tinha feito com o latim, a língua francesa popular e os dialetos regionais da França. O capítulo intitulado "Carta pras Icamiabas" é uma paródia da carta do escrivão Pero Vaz de Caminha que informa a descoberta do Brasil ao rei de Portugal. Como parte da paródia, a carta aos Icamiabas é endereçada na direção oposta à carta de Caminha: a partir do centro para a periferia, mas por meio de uma visão periférica. Escrito pelo protagonista Macunaíma, um índio negro ("retinto filho preto e do medo da noite") que se torna 
branco após o banho em uma fonte mágica, a carta informa a "descoberta" da cidade de São Paulo à tribo das Icamiabas. Seu estilo arcaico e rebuscado, em um português "camoniano", contrasta com o resto da narrativa. Entre outras fontes de estranheza, Macunaíma comenta que os paulistanos falam uma língua e escrevem outra (ANDRADE, 1984, p. 66). Na conversação diária, diz a carta, os paulistanos falam um idioma bárbaro, impuro, mas assim que eles começam a escrever eles empregam "a língua suave de Camões".

Uma das expressões mais comuns dessas tensões linguístico-ideológicas em um sistema literário é a paródia. Segundo Bakhtin paródia não é apenas uma imitação burlesca de uma obra conhecida: é parte do processo de estilização que gerou a prosa romanesca. $\mathrm{Na}$ estilização há pelo menos duas consciências discursivas. Como explica Bakhtin:

O heterodiscurso introduzido no romance (quaisquer que sejam as formas de sua introdução) é discurso do outro na linguagem do outro, que serve à expressão refratada das intenções do autor. A palavra de semelhante discurso é uma palavra bivocal especial. Ela serve ao mesmo tempo a dois falantes e traduz simultaneamente duas diferentes intenções: a intenção direta do personagem falante e a intenção refratada do autor. Nessa palavra há duas vozes, dois sentidos e duas expressões. Ademais, essas duas vozes são correlacionadas dialogicamente, como que conhecem uma à outra (como duas réplicas de um diálogo, conhecem uma à outra e são construídas nesse conhecimento recíproco), como se conversassem uma com a outra. A palavra bivocal é sempre internamente dialogada. (BAKHTIN, 2015, p. 113)

Como discurso bivocal, a paródia (ou estilização paródica, como Bakhtin também denomina) difere da estilização simples porque expressa alguma discordância estilístico -ideológica entre duas consciências linguísticas. Segundo Bakhtin, a estilização, simples ou paródica, é o principal procedimento de romancista. Estilização e paródia não se referem relações dialógicas que se referem apenas obras ou trechos identificados, mas ao estilo a e visão de mundo de diferentes discursos em confronto dialógico.

Como exposto uma das origens remotas da globalização e suas tensões culturais é a colonização. Mas o fenômeno pós-colonial designado como globalização inclui um novo fator: nunca as migrações foram tão rápidas, numerosas e intensas quanto atualmente. Como afirma Edward Said:

Porque, certamente, é uma das características mais infelizes desta época é ter produzido mais refugiados, migrantes, deslocados e exilados do que nunca antes na história, a maioria deles como consequência e, ironicamente, complementos de grandes conflitos pós-coloniais e imperiais. À medida que a luta pela independência criou novos estados e novas fronteiras, produziu também desabrigados, migrantes e nômades, não adaptados às novas estruturas de poder institucional, rejeitados pela ordem estabelecida por sua intransigência e obstinada rebeldia. E na medida em que essas pessoas vivem entre o velho o novo, entre o antigo império e o novo Estado, sua condição associa tensões, irresoluções e contradições na sobreposição dos territórios mostrados no mapa cultural do imperialismo. (SAID, 1994, p. 332)

Isso causa uma migração muito mais intensa de línguas (incluindo os dialetos locais), tradições e identidades culturais. Pessoas de diferentes origens, classes sociais e condições migram, muito mais - e bem mais rapidamente - que no passado. Hoje em dia, bem mais do que no passado, as cidades são cada vez mais multilingues e multiculturais. Nas grandes cidades de todo o mundo a língua oficial convive não só com variantes regionais, mas também com as línguas "exóticas". Com a migração oriunda das ex-colônias, a lín- 
gua do colonizador, depois de ter sido imposta durante séculos nas colônias, regressa aos seus países de origem - mas enriquecida com novo vocabulário novo, sotaques e traços culturais. Junto com a língua, também a cultura; própria identidade se torna híbrida, em um processo que nem sempre é pacífico.

$\mathrm{O}$ acesso de filhos de imigrantes à alfabetização e ensino superior criou um tipo de escritor que vive entre duas ou mais culturas. Hoje em dia, podemos encontrar um escritor inglês chamado Kazuo Ishiguro; ou um escritor do Caribe de língua inglesa e origem indiana chamado Vidiadhar Suraiprasad Naipaul; ou escritores de origem indiana ou egípcia que também são influenciados pela literatura ocidental e expressam o diálogo e os conflitos entre culturas, como Salman Rushdie e Nagib Mahfuz. Em alguns casos, os escritores têm uma identidade híbrida cujas tensões tentam representar e criticar em suas obras. O comentário abaixo de Said sobre intelectuais no exílio também é válido para o papel do intelectual local de identidade híbrida:

Embora possa ser uma extrema desonestidade panglossiana comparar as bravatas do intelectual no exílio com a miséria da pessoa deslocada, é possível, creio eu, ver no intelectual aquele que primeiro destila e articula os impasses que a modernidade desfigura - deportação em massa, prisões, transferência de população, espoliação coletiva e migração forçada. (SAID, 1994, p. 332-3)

O mundo globalizado, com sua complexidade e suas tensões linguísticas e culturais, é matéria para o romance contemporâneo. Cabe ao heterodiscurso do romance apresentar de maneira crítica essa situação, em que há muito a explorar. Pode-se, por exemplo, analisar a função e as novas configurações do romance como uma expressão do relativismo cultural em um mundo que perdeu a fé em grandes narrativas, como afirma Jean-François Lyotard. Haveria também muito a se aproximar no papel do romance de desconstruir outras identidades, tais como sexo e raça. Há também a acentuação de uma característica fundamental do romance, segundo Bakhtin: a capacidade de assimilar e reelaborar, pondo em diálogo, discursos diversos, ultrapassando a fronteira do discurso literário, como no caso de metaficção historiográfica, analisada por Linda Hutcheon, narrativa metalinguística que se assemelha à transdisciplinaridade praticada no discurso acadêmico.

Por razões de escopo e unidade, limitei minhas reflexões sobre questões culturais e linguísticas e alguns, tendo em conta que um fenômeno tão complexo como a globalização envolve muitos outros problemas, alguns deles apenas mencionados neste ensaio. Concluo exemplificando com uma situação narrada no romance Terra Sonâmbula pelo ficcionista moçambicano Mia Couto. Os protagonistas desse romance são um menino chamado Muidinga e um velho chamado Tuahir. O menino perdeu a memória, mas não se esqueceu a habilidade da leitura; o velho é analfabeto, mas detém a memória oral. Em um país devastado pela guerra, ambos os personagens resistem psicologicamente com o auxílio de narrativas. Muidinga lê para Tuahir os diários de Kindzu, vítima da guerra, encontrados em um ônibus queimado. Esses cadernos apresentar um texto híbrido, em que o texto escrito é permeado de influência oral, vocabulário e maravilhoso local. A leitura em voz alta dos cadernos de Kindzu por Muidinga é parte de um amplo diálogo em que Muidinga fascina Tuahir com performance da leitura e Tuahir protege Muidinga com seu conhecimento tradicional dos recursos da terra.

A melhor possibilidade de globalização é aquela em que o padrão global da linguagem inclui a alteridade de vozes locais. Como o romance, na concepção de Bakhtin, é uma forma híbrida, há casos em que o romancista, como um artista da palavra que pode ex- 


\section{Conexão Letras}

pressar os vários mundos culturais cujos traços atuam na caracterização de seus personagens - colocando-os em confronto dialógico. Nessas confrontações, o romancista utiliza a estilização e a paródia para criar, criando híbridos como expressão não só do encontro e mútua influência de diferentes culturas, mas também de identidades híbridas. É possível concluir que as tensões entre diferentes culturas, geralmente com assimetrias de status e poder, favorecem a criação integral dos discursos paródicos, bem como outras características carnavalescas como as analisadas por Bakhtin na obra de Rabelais (BAKHTIN, 1984). No Brasil tal procedimento foi chamado, por Oswald de Andrade (1890-1954), antropofagia: não rejeitar a língua e a cultura colonial nem ser assimilada por ela, mas criar um híbrido, expressão paródica, irônica. Este é o tipo de resposta dada por diversos romancistas de países colonizados. Isto também pode ser a resposta de escritores de países centrais multiculturais para as padronizações impostas pela globalização.

\section{Referências}

ANDERSON, B. Imagined communities: reflections on the origin and spread of nationalism. London: Verso, 1991.

ANDRADE, M. de. Macunaíma. Belo Horizonte: Itatiaia; Brasília: INL, Fundação Nacional Pró-Memória, 1984.

BAKHTIN, M. Os gêneros do discurso. In: Bakhtin, M. Estética da criação verbal. Tr. Paulo Bezerra. São Paulo: Martins Fontes, 2003.

. M. Teoria do romance I: a estilística. Tr. Paulo Bezerra. São Paulo: Editora 34, 2015. Rabelais.

M. A cultura popular na Idade Média e no Renascimento: context de François

M. Rabelais and his world. Tr. Hélène Iswolsky. Bloomington: Indiana University Press. 1984.

BARBOSA, A. de F. O mundo globalizado: política, sociedade e economia. São Paulo: Contexto, 2007.

BAUMAN, Z. Globalização: as conseqüências humanas. Tr. Marcus Penchel. Rio de Janeiro: Jorge Zahar, 1999.

BHABA, H. K. O local da cultura. Tr. Myriam Ávila, Eliana Lourenço de Lima Reis, Gláucia Renate Gonçalves. Belo Horizonte: Editora da UFMG, 1998.

BOSI, A. Dialética da colonização. São Paulo: Companhia das Letras, 1992.

BRANDÃO, J. J. L. A invenção do romance: narrativa e mimese no romance grego.

Brasília: Editora da UnB, 2005.

CANCLINI, N. G. Culturas híbridas: estratégias para entrar e sair da modernidade. São Paulo: Edusp, 2001.

CARRREIRA, S. de S. G. 'Vestígios de transculturação em Shame, de Salman Rushdie'. Revista eletrônica do Instituto de Humanidades. V. 3, No. 11, October/

December, 2014. Site: http://publicacoes.unigranrio.com.br/index.php/reihm/article/ viewFile/463/454. Accesso em 01.10.2014.

COUTO, M. Terra sonâmbula: Rio de Janeiro: Nova Fronteira, 1995.

DEFARGES, P. M. La mondialisation. Paris: PUF, 2012

HALL, S. Da diáspora: identidades e mediações culturais. Belo Horizonte: Editora da UFMG, 2003. 
. S. A identidade cultural na pós-modernidade. Tr. Tomaz Tadeu da Silva e

Guacira Lopes Louro. São Paulo: DP\&A, 1999.

HUTCHEON, L. Poética do Pós-Modernismo: História, Teoria, Ficção. Rio de Janeiro:

Imago, 1991.

IANNI, O. Teorias da Globalização. Rio de Janeiro: Civilização Brasileira, 2008.

IORIS, R. R. Culturas em choque: a globalização e os desafios para a convivência multicultural. Rio de Janeiro: Annablume, 2007.

LINS, O. Avalovara. São Paulo: Companhia das Letras, 2005.

. O. Avalovara. Tr. Gregory Rabassa. New York: Dalkey Ed. 2002.

. O. Evangelho na taba: novos problemas inculturais brasileiros. Org. Julieta de

Godoy Ladeira. São Paulo: Summus Editorial: 1979.

LYOTARD, J-F. A condição pós-moderna. Rio de Janeiro: José Olympio, 1996.

MARAZZINI, C. Breve storia della lingua italiana. Bologna: Il Mulino, 2004

SAID, E. Cultura e imperialismo. Tr. Denise Bottman. São Paulo: Companhia das

Letras, 1995.

SAID, E. Culture and imperialism. New York: Vintage Books,1994.

RUSHDIE, S. Midnight's children. London: Vintage, 1995.

SANTOS, M. Por uma outra globalização: do pensamento único à consciência universal. Rio de Janeiro: Record, 2008.

SAUSSURE, F. de. Curso de Linguística Geral. Tr. Isidoro Blikstein. São Paulo:

Cultrix, 2001.

SILVA, T. T. da (org.). Identidade e diferença: a perspectiva dos Estudos Culturais. São Paulo: Vozes, 2008.

ORTIZ, R. Mundialização: saberes e crenças. São Paulo: Brasiliense, 2006. . R . Mundialização e cultura. São Paulo: Brasiliense, 1994. 